\title{
Enabling the U.S. Engineering Workforce to Perform: Building Organizational Sustainability for Innovation in Professional Graduate Engineering Education
}

\author{
S. J. Tricamo, ${ }^{1}$ D. R. Depew, ${ }^{2}$ A. L. McHenry, ${ }^{3}$ D. D. Dunlap, ${ }^{4}$ \\ D. A. Keating, ${ }^{5}$ T. G. Stanford ${ }^{5}$

\begin{abstract}
New Jersey Institute of Technology ${ }^{1} /$ Purdue University $^{2} /$ Arizona State University East $^{3}$ Western Carolina University ${ }^{4} /$ University of South Carolina $^{5}$
\end{abstract}

\begin{abstract}
This is the second paper in the panel session of the National Collaborative Task Force for reform of professionally oriented engineering graduate education to make it more relevant to the needs of industry and to ensure a strong U.S. engineering workforce for competitiveness. The mission, purpose, methods, motivations, talents, and experience of engineering professionals who conceptualize, design, develop, innovate, and lead the purposeful development of new and improved technology are quite different from those of the academic scientific researcher. It is now evident that innovative professional graduate education programs do not fit organizationally into traditional disciplinary research-oriented academic departments. This paper focuses on new types of innovative organizations that are required to initiate, develop, and sustain high-quality professional graduate education at $21^{\text {st }}$ century universities in collaboration with industry. This paper begins the exploration of new types of innovative learning organizations that must be implemented into the mainstream of university operations. These organizations must foster a collaborative engineering culture for technological creativity, innovation, and technological leadership that enable the continuous growth of working professionals through all levels of engineering responsibility in industry.
\end{abstract}

\section{Introduction}

As we enter the $21^{\text {st }}$ century, the practice of engineering for systematic technological innovation has changed from the conventional linear model of basic research-driven innovation to a systematic and integrative model of needs-driven engineering innovation that integrates purposeful creative engineering development with directed-strategic research; and engineering and technology graduate education must reflect this change for the United States to maintain its competitive edge in the innovation-driven economy. The demand for engineers with strong technical skills, practical engineering experience, and professional skills for leadership of technology development in industry is increasing. In today's innovation-driven economy, the nation's domestic engineering workforce plays a primary and integral role in generating, developing, and leading continuous technological innovation for competitive advantage. Although U.S. engineering education has pioneered various professional options including fiveyear undergraduate and master's models as preparation for practice, a system that fosters highquality postgraduate professional education throughout the professional's career in combination

"Proceedings of the 2004 American Society for Engineering Education Annual Conference and Exposition Copyright $\odot$ 2004, American Society For Engineering Education 
with practice needs to be fully developed to augment the nation's strength in research-based graduate education.

The purpose of this paper is to establish a solid conceptual framework for the design of postgraduate professional engineering education as a "system for lifelong learning".

\subsection{How does Professional Engineering Differ from Research Engineering?}

To meet the challenges for enhanced educational engagement with industry and for purposeful reform that develops postgraduate professional education as an integrated system for lifelong learning, the GSD-National Collaborative in Engineering and Technology Graduate Education believes that a clear distinction must be made between traditional graduate education for academic scientific research and that of innovative professionally oriented postgraduate education for advanced engineering practice and leadership of creative technology development and innovation in industry. We believe that the characteristics that differentiate these two different types of graduate education can be distinguished best by using modern definitions of the meanings of engineering and technology themselves as they have evolved in the $21^{\text {st }}$ century. These definitions are as follows:

- "Engineering is a creative profession concerned with the combining of human, material, and economic resources to meet the needs of society ... for the advancement and betterment of human welfare. Engineers and technologists create, design, and lead the purposeful, systematic development of new innovative technology in the form of new and improved products, processes, systems, and operations responsive to real-world needs. In this process, they use the integrative method of engineering as a purposeful and systematic practice for innovation, entrepreneurship, and responsible leadership driven by an innovation ethic for betterment that is responsive to real-world needs.

Whereas strategic directed scientific research that is often necessary to gain a better understanding of physical phenomena is frequently required during the purposeful, systematic technology development process, scientific research is not the primary driver. Creative engineering practice requires proactive responsible leadership beginning with the identification of meaningful real-world needs. During the creative technology development process, however, engineers and technology leaders must anticipate the need for strategic directed scientific research and know also when and how to integrate this activity for effective technology development."

\section{- GSD-National Collaborative Task Force}

- $\quad$ "In its broadest sense, technology is the process by which humans modify nature to meet their needs and wants. However, most people think of technology only in terms of its artifacts ... But technology is more than its tangible products. An equally important aspect of technology is the knowledge and processes necessary to create and operate those products, such as engineering know-how and design,

"Proceedings of the 2004 American Society for Engineering Education Annual Conference and Exposition Copyright @ 2004, American Society For Engineering Education 
manufacturing expertise, various technical skills, and so on. Technology also includes all of the infrastructure necessary for the design, manufacture, operation, and repair of technological artifacts from corporate headquarters and engineering schools to manufacturing plants and maintenance facilities."

Committee on Technology Literacy-2002

National Academy of Engineer

\subsection{Skill Sets of the Professional Engineer}

As Fred Gary, former vice president of corporate engineering and manufacturing at General Electric, pointed out:

"Development is the primary task of engineers ... Great engineering is measured by the proper gauging of people's needs and the delivery of affordable, high-grade products and services."

However, development is quite different from research. As Martino, formerly of the Air Force Office of Scientific Research, stated:

"The term "research" is defined here as an attempt to acquire new knowledge about some phenomenon in the universe, or about some phenomenon in an abstract model of a portion of the universe, which is not necessarily made with an application in mind. The definition makes no distinction between basic and applied research, since the difference between the two terms is usually in the motivation of the researcher ... There is, however, a meaningful distinction between research and development: development is an attempt to construct, assemble, or prepare for the first time, a device, material, technique, or procedure, meeting a prescribe set of specifications or desired characteristics and intended to solve a specific problem. This definition includes not only mechanical devices and hardware, but also such things as computer programs, chemicals, and other materials. The essence of this definition is that development is intended to meet some set of specifications in order to solve a specific problem ... Research and development are two entirely different categories of activity, and there is no neat linear progression from one into the other ... The kindest thing one can say for the (linear) model is that it is erroneous."

\subsection{Areas of Competency of Professional Engineers}

In order to compete, professional engineering education should be viewed in a much broader sense than ever before. No longer can the United States afford to view engineering education as limited to the undergraduate level or to the misperception that engineering is a byproduct of research. The career paths for development and research are different. In addition, graduate education in engineering must reflect this difference, because one type of graduate education does not fit all purposes or all missions.

"Proceedings of the 2004 American Society for Engineering Education Annual Conference and Exposition Copyright @ C 2004, American Society For Engineering Education 
If we are to unlock the creative, innovative, and leadership talent of our domestic engineering workforce, then we must take purposeful action to better develop the nation's higher educational infrastructure to better support what engineers do and are responsible for doing in industry and government service to sustain constant technological innovation. During the last decade there has been substantial criticism from industry and academia itself concerning several "competency gaps" that newly hired engineering graduates seem to exhibit relevant to the ability to actually practice creative engineering to meet real-world needs. Much of this criticism concerning the characteristics and skill-sets that we desire in experienced engineers is well deserved. The criticisms cover the gamut and identification of critical professional gaps from business knowledge/skills; project management; written communication; oral communication/listening; international perspective; product/process design; open-ended problem solving through higher order multidisciplinary and systems thinking. Undergraduate engineering education cannot develop all of these skills within a four-year curriculum. There is no doubt that undergraduate education can begin to develop many of these critical skill-sets for engineering practice. However, as Spitzer has pointed out:

"It never has been possible to teach bachelor's level individuals everything they will ever need to know - although the educational system has behaved for many years as if this were a possible achievement."

But as Cranch, former Dean of Engineering at Cornell, has pointed out:

- "Much of the attention given to graduate study in engineering has focused on doctoral research, with the master's degree viewed as merely a steppingstone on the path to the Ph.D. ... This emphasis on research is largely patterned after the physical sciences, where the traditional goal has been scholarly research ... But a career in engineering is different from a career in the sciences ... As the industrial revolution pushes wider and deeper into almost all realms of human activity, it is bringing about a marked change in the work force, with a growing number of functions requiring a substantial level of skill and sophistication ... These changes mean increased educational requirements in all fields of engineering ... The volume of material that must be taught is so great that it simply cannot be accommodated within the traditional four-year undergraduate curriculum ... It is important to recognize that professional goals change during the course of an engineer's career. As engineers get older, many assume management responsibilities or enter a more multidisciplinary environment ...From a curricular perspective, multidisciplinary work requires a knowledge base and maturity that is almost impossible to create at the bachelor's level."

\subsection{Education of the Professional Engineer: Context-Based Learning}

For the past four decades, engineering education, particularly at the graduate level, has been oriented toward engineering research. The change in this trend will be driven by real world demands on the engineering professional and the educational expertise of that professional. It is

"Proceedings of the 2004 American Society for Engineering Education Annual Conference and Exposition Copyright (C) 2004, American Society For Engineering Education 
clear an engineer's education benefits from immersion in dealing with problems of the real world, that is, education in the context of application, or context-based learning.

This reform will be far more extensive than a simple update of course content. Rather it will change the process of engineering education to one that teaches how to deal with even the most complex of issues, a context-based approach where both student and faculty are one in their pursuit of learning, innovation, and creation of new economic opportunities.

Engineering professionals must be proficient in diagnosing problems associated with specific applications, abstracting their controlling constituents, and using known technical principles to arrive at sound, practical solutions.

\subsection{Problems Associated with Establishing Professional Engineering Graduate Programs}

The need to develop a graduate engineering curricula meeting the needs of professional engineers has been well documented. Current research-oriented graduate engineering problems address basic research that typically does not reach the application stage for many years, if at all. The need for programs to educate professional engineers capable of making immediate contribution to the technical innovation needed to support a growing economy must be met.

One of the major problems that must be addressed is how to maintain research oriented graduate engineering education that is designed to prepare students for academic careers while simultaneously creating a new graduate program focused on the education of the professional engineers needed by industry.

\subsection{Research Faculty}

Research faculty has a personal stake in not changing the current culture in graduate engineering education. For the most part, their skills have been developed to carry on research activities in a narrow area of specialization. They have not had extensive experience in applied research or satisfying the professional needs of industry.

Research faculty's activities are directed toward fulfilling the requirements they see as necessary for a successful career in a research university. These include:

- the need to publish research results;

- the need to increase their stature and standing in their field;

- the development of funding sources;

- promotion and tenure; and

- the need to keep abreast of current research done in their field of specialization.

These interests are not compatible with those of faculty teaching in a program focusing on professional engineering. If current faculty perceive that the introduction of a graduate program in professional engineering is intended to replace research programs, their opposition will prevent such a new program to be implemented. Therefore, they must be made to understand that this is not intended. Programs directed at engineering research will not be replaced, nor

"Proceedings of the 2004 American Society for Engineering Education Annual Conference and Exposition Copyright (C) 2004, American Society For Engineering Education 
should they be. Rather, the professional engineering graduate programs will supplement the research programs, not replace them.

\subsection{Various Methods of Implementing a New Professional Engineering Graduate Program}

\subsection{Department-Based}

Even if the professional program is a supplement to the research program, there will be resistance from current faculty if an attempt is made to add new degree programs to the current departmental structure. Some faculty may perceive this addition as incompatible with the research program and will tend to evaluate the program in terms of the same metrics that exist in the research program. For example, they will probably object to any equivalent to a doctoral dissertation, should such a requirement be part of the professional program, as lacking the requirements of furthering research in their field.

There will also be a mismatch in terms of background, expertise, and interests. Therefore, a department-based structure will lead to a bifurcated educational program with diverse interests, goals, and professional requirements. If it could be implemented, it would not likely exist for very long.

\subsection{Interdisciplinary Program}

A better approach would be to create a separate program to serve the educational needs of the professional engineer. There is precedence in the academic community for the formulation of interdisciplinary programs that bring together several disciplines and organizationally operate as a program rather than a department. These programs are under the direction of a faculty member with an interest in creating the program and typically draw faculty from several departments. In some ways it is structured like a matrix organization, and carries some of the problems inherent in such a structure. For example, faculty drawn from different departments are evaluated by two different administrators - the head of their home department and the head of the interdisciplinary program. Often, such an arrangement leads to less credit being given to faculty by their home department.

\subsection{Institute Structure}

A third possibility would be to step further away from the academic structure of the university by creating a stand-alone Institute which will carry out the educational program and be capable of working with industry on a contractual basis to complete industrial projects. This type of organization has been used successfully by some universities and, because of its more autonomous nature, professional graduate programs can be more easily established and administered. This organizational structure also has the advantage of having a closer tie to industry and industrial resources, such as personnel to teach in the professional program. Unfortunately, this organizational structure is the most difficult of the three to form and sustain because of funding requirements.

"Proceedings of the 2004 American Society for Engineering Education Annual Conference and Exposition Copyright (C) 2004, American Society For Engineering Education 


\subsection{When to Approach College Administrators}

Before presenting a new program such as the professional engineer graduate program to university administration, there are several principles that must be kept in mind. Briefly, they are as follows:

- Do not go to the administration requesting funds. Administrators know from many passed experiences that when unsolicited visits by faculty are made, at some point a request for funding will be forthcoming. These requests are usually accompanied by statements from the faculty member to the effect that the funded project will surely be successful - a promise usually made without any meaningful substantiation.

- Have funding in hand, perhaps from a funded proposal or by solid commitments form industry to provide funding. Solicited letters of support from industry that do not contain specific commitments, such as funding or sponsorship of students to enroll in the program, are useless.

- Prepare a brief business plan for the new program which includes a review of the potential market, similar programs now available, existing and potential sponsors from the public and private sector, what the administrative structure of the program will be, how the program will be integrated into the university structure, a projection of start-up costs and potential enrollment, and income projected over a five-year time frame.

- Include a description of the Collaborative and a brief recounting of its history, plans, and support. Emphasize that it already exists, is functioning, is growing, and has attracted the support of the some of the leading national and international companies.

Several important points will be made by this presentation. They are:

1. You are telling the administration what you can do for the university, not what it can do for you.

2. The program does not need initial funding from the university. Financial support from industrial sponsors and foundations is already in place.

3. The collaborative will succeed, and it will reflect very positively on the school and its administration if they are on board at the beginning of the journey.

4. In most cases, there are a significant number of industrial members on the university's Board of Trustees and other industrial advisory groups. They have made it known that they would like to have students better prepared for working in industry. This program will respond to this long felt need.

5. You understand the market and you have a detailed plan for implementation of the program. 


\subsection{Conclusion}

Clearly, many more problems need to addressed to implement and sustain this program. However, given the importance of significantly increasing the talent pool that contributes to the economic growth of the country, these problems can and will be solved.

\section{Biography}

DONALD A. KEATING is associate professor of mechanical engineering, University of South Carolina, former dean Engineering and Science Institute of Dayton, former technical director, Air Mobility Program, Hqs USAF Aeronautical Systems Division.

THOMAS G. STANFORD is assistant professor of chemical engineering, University of South Carolina.

DENNIS R. DEPEW is professor and dean of the school of technology, Purdue University.

ALBERT L. McHENRY is dean of the college of technology and applied sciences at Arizona State University East, and former Chair of the Engineering Technology Council of the American Society of Engineering Education.

DUANE D. DUNLAP is professor and department head of engineering technology, Western Carolina University.

STEPHEN J. TRICAMO is professor of industrial and manufacturing engineering, and former dean of engineering and technology, New Jersey Institute of Technology.

"Proceedings of the 2004 American Society for Engineering Education Annual Conference and Exposition

Copyright (C) 2004, American Society For Engineering Education 